menoscabo alguno de los innegables méritos de esta edición, que todos los investigadores de la prosa castellana medieval agradecerán sinceramente. Esperamos que la publicación se continúe muy pronto, hasta verse del todo consumada. El comienzo no ha podido ser más prometedor.

El Colegio de México.

JUAN M. LOPE

\title{
Joaguín González Muela, El infinitivo en "El Corbacho" del Arcipreste de Talavera. Universidad de Granada, 1954 (Colección filológica, 8).
}

Debido a la escasez de estudios sobre sintaxis histórica española, todos los trabajos que sobre tal aspecto del lenguaje puedan publicarse serán siempre muy bien venidos. El ensayo de González Muela continúa una labor ya iniciada hace varios años, en forma general, por W. A. BeArdsLEY, cuyo libro sobre Infinitive constructions in Old Spanish (New York, 1921) no ha sido superado.

Grandes dificultades ha tenido que vencer el autor, en especial las originadas por la falta de una metodología sintáctica y por la escasez de estudios similares anteriores. Voluntariamente, se limita a estudiar las particularidades sintácticas del infinitivo en el Corbacho, sin entrar en comparaciones con el uso del infinitivo en otras obras del siglo $\mathrm{xv}$ o de la Edad Media. El librito, por ello, más que un estudio de sintaxis histórica, es un ensayo de gramática descriptiva, muy útil para quien intente hacer el análisis idiodiacrónico de nuestra lengua.

La obra aparece dividida en tres capítulos, en donde se estudian, respectivamente, las perifrasis de infinitivo, las construcciones de infinitivo con acusativo, dativo y nominativo, y los infinitivos independientes (inf. absoluto). En el primer capítulo, que es el más amplio y, en mi opinión, el más completo y conseguido, el autor estudia los distintos significados de cada perífrasis según la naturaleza del verbo auxiliar y según la propia significación del infinitivo. Analiza también el orden en que aparecen colocados los diversos elementos de las perífrasis, cosa que también hace en el capítulo segundo, donde ofrece una clara estadística del orden mantenido por el infinitivo, el verbo domi-

"qué cosa es paraýso" $27_{52}$ y $29_{3}$, frente a "es el paraýso" $29_{2}$ y "et las yerbas" $27_{5 \pi}$. Faltas de concordancia en el número no son raras en textos medievales; por ello quizá se pueda leer deve, en singular, en los dos casos seguidos de $121_{1 \pi^{-18}}$.

No parece conveniente corregir acançar (p. 95 $)$ en a[l]cançar, ya que la primera forma se encuentra todavia en Santa Teresa (C. Fontecha, Glosario, p. 3; cf. también Romera-Navarro, Registro, p. 34). Las lagunas que los editores rellenan suelen ser muy breves y de reconstrucción segura; por esta misma cautela, haría falta declarar los motivos por los que algunas palabras o frases de mayor extensión (pp. $111_{3:}, 117:$, $129_{73^{*}}$ por ejemplo) aparecen entre corchetes (¿lagunas del manuscrito? ¿cambios exigidos por el sentido? ¿pasajies borrosos?), de manera que el lector pueda apreciar siempre las garantias que tales enmiendas ofrecen. Explicaciones que podrian hacerse en notas al fin del texto original, según el método empleado por el mismo Castro y Calvo en su ed. del Libro de la caza (Barcelona, 1945). Quizá tampoco sea necesario repetir ante en $129_{96}$, ya que puede tratarse de una simple anteposición preposicional. Otras de las enmiendas podrian tal vez no ser absolutamente necesarias (de 6 $\mathrm{I}_{52}$, puestos $79_{130}$, es $102_{10}$, ca $\log _{55}$, ¿oración causal yuxtapuesta?). 
nante y el acusativo, dativo o nominativo que les acompaña. En las pp. 91-93, expone el autor las conclusiones (de carácter estilístico o puramente gramatical) que del análisis se deducen. Las dos principales son: el cruce de la tendencia culta, del latinismo consciente, con la tendencia vulgar, lógica en una obra de inspiración popular; y el estado sintáctico avanzado, muy próximo al del castellano actual, a pesar de los cultismos que salpican la obra.

El libro incluye también el estudio, aunque breve, de las formas concurrentes a estas construcciones infinitivas, complemento importante para poder apreciar la frecuencia relativa con que el infinitivo se usa en el Corbacho. Algunas observaciones que el autor ofrece son de gran utilidad para establecer la cronología de ciertas construcciones cuya forma vaciló durante la Edad Media ${ }^{3}$. La bibliografía con que se cierra la obra incluye los más importantes estudios sintácticos sobre el tema².

Indudablemente que el estudio de González Muela será de mucha utilidad para los trabajos futuros de igual carácter; por ello, y por el acierto con que analiza muchas construcciones, debemos felicitar sinceramente al autor. Sin embargo, y precisamente por el interés que tiene el libro, me permitiré hacer algunas observaciones que quizá puedan ser de alguna utilidad.

Los sutiles matices significativos de algunas de las construcciones estudiadas permitirian discutir la interpretación que de ellas ofrece el autor. Por ejemplo, en el $\$ 24$ se afirma que las perífrasis formadas con el auxiliar entender tienen el mismo significado que las dependientes de creer; en mi opinión, la semejanza es más con 'pensar', 'desear', 'proyectar": "en esta... obra... que a su servicio e loor... entiendo fazer" (cf. fr. entendre 'tener intención de', ingl. to intend). En el ejemplo 128.7 ("Seer la muger tomadora, vsurpadora a diestro e syniestro, poner en ello dubda sería gran pecado", p. 97) la oración de infinitivo no es, de ningún modo, sujetiva". Los ejemplos 169.10 y 170.22 estudiados en la p. 33 ("óuole de esconder") quizá no expresen el simple "acaecimiento subsiguiente", sino la necesidad determinada por el hecho principal ${ }^{t}$. En distintos pasajes del ensayo hemos encontrado construcciones que se estudian independientemente, y que acaso fuera conveniente reunir, dada la proximidad de su significado: querer más (p. 15), querer antes (p. $6_{4}$ ) y amar más (p. 48 ) en oraciones comparativas son perífrasis que expresan, no la simple voluntad, como indica el autor, sino la p r e ferencia del primer término de la comparación sobre el segundo.

1 Tal es el caso del infinitivo dependiente de comengar, que en castellano antiguo podía construirse sin preposición o ir regido por a o de. En el Corbacho predomina ya la forma moderna con $a$, pero todavía aparecen algumos casos con de; el infinitivo puro, sin embargo, no aparece ya en la obra del Arcipreste.

2 Se observa la falta de algunos artículos valiosos, como los de Strausbaugh (sobre

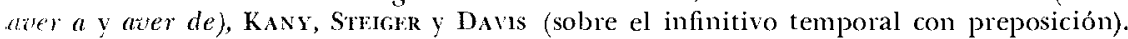

: Comparese esta construcción con otras que el autor cita en la página siguiente, y que él mismo considera como simples aposiciones: "La muger amar al ombre de voluntad pura e coracón verdadero, non ay regla que lo diga". Cf. $l o=$ la muger amar al ombre; en ello $=$ en seer la muger tomadora...

* No sería justo citar otros casos de difícil interpretación (por ejemplo, el infinitivo de $133.15, p, 17$, en el que quizá haya algún matiz desiderativo), ya que su valoración presenta dificultades que cada estudioso resolvcría de manera diferente. 
En el método de clasificación podría observarse un poco de irregularidad, ya que el autor mezcla las clasificaciones hechas atendiendo a los significados de las perítrasis (criterio seguido generalmente) con las hechas atendiendo a los tiempos en que se encuentra el verbo auxiliar (saber, $\$ 18$ ), o al orden de las palabras (mandar, $\$ 16)$, o a la persona en que se halla el verbo conjugado, criterio este último cuyo valor no alcanzamos a comprender.

Sin embargo, el mayor reparo que puede hacerse al libro es el de su parcialidad. El estudio es incompleto, cosa que no puede apreciarse por el título de la obra, demasiado general y ambicioso. No solamente se omite el estudio de muchos de los usos del infinitivo que ofrece el Corbacho $o^{5}$, sino que incluso dentro de las construcciones infinitivas estudiadas se observan lagunas inexplicables. Por ejemplo: como ya hemos indicado, la mitad de la obra se dedica al estudio de las perífrasis de infinitivo; pues bien, simplemente en el prólogo del Arcipreste (siete páginas en la ed. de Simpson) se encuentran dos construcciones perifrásticas que González Muela no menciona ${ }^{6}$.

Es de esperar que en la próxima edición del libro subsanará su autor todas estas pequeñas deficiencias, de poca monta frente a la utilidad indiscutible de su investigación.

Fl Colegio de México.

JUAN M. LOPE

Manuel García Blanco, Don Miguel de Unamuno y sus poesias. Universidad de Salamanca, 1954; $453 \mathrm{Pp}$.

Don Manuel García Blanco, el excelente editor y comentarista de Unamuno, nos da aquí un detalladísimo estudio biográfico-cronológico de la actividad poética de don Miguel. El libro no es, ni pretende ser, un estudio de la poesia de Unamuno, sino de sus poesías. Apoyándose con precisión y minuciosidad en el inagotable material bibliográfico a

"He aquí algunas construcciones de las que nada se dice (cito por la ed. de L. B. Simpson, Berkeley, 1939): I) infinitivo con preposición, complemento de un nombre (que de non saber seria ynposyble, p. 15); 2) inf. usado como sustantivo (el amar): 3) inf. usado como nombre y como verbo conjuntamente (seria titile cosa e santa dar canesa comuniente); 4) inf. con preposición formando oración subordinada: a) inf. con de condicional (fuera de ser por hordenado matrimonio... ayuntados, p. 11); b) callsal, con por (por querer seguir el apetyto, pp. 5 y 7 ); c) modal, con en (el que su tienpo e dias en amar loco despiende, p. 8); d) final, con para o por (para se defender, p. 4); e) de tiempo, con al, etc.; 5) perífrasis inceptiva 'estar a punto de' + inf. (esto en pumto de rascarme o de me mesar toda, ejemplo citado por el mismo autor en otro lugar, p. 116); 6) inf. independiente, con valor adversativo, introducido por "en guar de" (en guar de medrar, desmedro. En guar de fazerme paños metos..., p. 128; en guar de llamar, suplicar e innocar a N. Señor, p. 264; en guar de conoscer scnorio, p. 147$)$.

- El autor estudia en el $\$ 20$ la perífrasis formada con plazer, y clasifica su empleo en cuatro grupos, según que el auxiliar vaya, a) en presente de indicativo, $b$ ) en pretérito de indic., $c$ ) en futuro de indic. y $d$ ) en imperfecto de subjuntivo; pero en la p. 3 de la ed. de Simpson aparece tal perifrasis usada en futuro de subjuntivo (con tres infinitivos): “aquellos que les pluguiere leerlo, e lev́do rretenerlo, e rretenido por obra ponerlo". Asimismo, la perifrasis con quever de la p. 5 ("por querer seguir el apetyto... quiere perder aquella gloria... del Paraýso) tiene un matiz ( $=$ 'deja, permite) que no coincide con ninguno de los cinco que el autor recoge. 